\title{
A política salarial dos professores da educação básica e a política de fundos: Fundef e Fundeb em questão
}

\author{
The basic education teachers wage policy and funding \\ policy: Fundef and Fundeb in question
}

Eldra Carvalho da Silva1

\section{RESUMO}

O artigo caracteriza-se pelo cotejamento da atual configuração da política salarial para os professores da Educação Básica no Brasil por meio das políticas de fundo em que destacamos o FUNDEF e FUNDEB. O estudo é parte da pesquisa "A política salarial para o profissional do magistério da educação básica da rede municipal, no contexto do FUNDEB nos municípios de Óbidos e Oriximiná- Pará", cujo objetivo é analisar a política salarial como aspecto de valorização do profissional da educação no contexto do FUNDEB, visando identificar e compreender os impactos trazidos para a política salarial dos professores, tomando como lócus de análise os municípios de Óbidos e Oriximiná, situados à região Oeste do Estado do Pará.

PALAVRAS-CHAVE: Política Salarial, FUNDEF, FUNDEB.

\begin{abstract}
The article is characterized by mutual comparison of the current configuration of the salary policy for teachers of Basic Education in Brazil through policies that emphasize the background and FUNDEF FUNDEB. The study is part of the research "The wage policy for the professional teaching of basic education in the municipal, in the context of FUNDEB in the towns of Obidos and Oriximiná-Para", whose objective is to analyze the wage policy as an aspect of appreciation of the professional education at FUNDEB, to identify and understand the impacts brought to the salary policy for teachers, taking as the locus of analysis and the cities of Óbidos Oriximiná, situated to the west of Pará State.
\end{abstract}

Keywords: Wage Policy, FUNDEF FUNDEB. 
No artigo 71, da Lei N. ${ }^{\circ}$ 4.320, de março de 1964, que estatui Normas Gerias de Direito Financeiro para Elaboração e Controle dos Orçamentos e Balanço da União, dos Estados, dos Municípios e do Distrito Federal, está expresso que "constitui fundo especial o produto de receitas especificadas que, por lei, se vinculam à realização de determinados objetivos ou serviços, facultada a adoção de normas peculiares de aplicação" (BRASIL, 1964).

Nesse sentido, Gemaque (2004) afirma que, analisando por essa ótica os fundos são vistos como mecanismos potencialmente capazes de suprir as deficiências de determinado setor, podendo ser constituído por recursos de diferentes procedências e destinado a um fim específico, como é o caso dos Fundos para financiar a educação.

Segundo Gemaque (2004), na década de 1990, a discussão sobre a constituição de fundos para financiar a educação é retomada, por ocasião da elaboração do Plano Decenal de Educação para Todos, em virtude de acordos assumidos na Conferência de Educação para Todos, realizada em Jomtien, na Tailândia, em 1990, e promovida pelo Programa das Nações Unidas para o Desenvolvimento (PNUD), pela Organização das Nações Unidas para a Educação, a Ciência e a Cultura (UNESCO), pelo Fundo das Nações Unidas para a Infância (UNICEF) e pelo Banco Mundial.

Nessa retomada de discussão de criação de fundos para financiar a educação, é importante destacar que, para os organismos multilaterais, como o Banco Mundial, por exemplo, seria preciso investir em determinados aspectos e, dentre estes, a carreira, a formação e o salário dos docentes. Esses pontos se constituem em destaques para se conseguir qualidade na Educação. Para isso era preciso disponibilizar recursos para que tais investimentos fossem realizados. E, assim, para alcançar tais objetivos "foi proposto que Fundos e mecanismos não-convencionais fossem criados e que os gastos públicos com educação fossem aumentados para além dos mínimos estabelecidos constitucionalmente, por meio de incremento de receitas" (GEMAQUE, 2004, p. 45).

Segundo Gemaque (2004), foi esse contexto que subsidiou a criação do Fundo de Manutenção e Desenvolvimento da Educação Básica e de
Valorização do Magistério (FUNDEF) com o propósito de universalizar o Ensino Fundamental, eliminar o analfabetismo e melhorar a qualidade da educação, para a qual o investimento no professor foi destacado como aspecto fundamental, portanto não aconteceu de forma como havia sido previsto.

O FUNDEF foi instituído por meio da Emenda Constitucional n. ${ }^{\circ}$ 14, aprovada em 12 de setembro de 1996, cujo art. 5..$^{\circ}$ alterou o art. 60, do ADCT, e passou a ter a seguinte redação:

Nos dez primeiros anos da promulgação desta emenda, os Estados, o Distrito Federal e os Municípios destinarão não menos de sessenta por cento dos recursos a que se refere 0 caput do art. 212 da Constituição Federal, a manutenção e ao desenvolvimento do ensino fundamental, com 0 objetivo de assegurar a universalização de seu atendimento e a remuneração condigna do magistério (BRASIL, 1996).

Com a aprovação da EC N. ${ }^{\circ}$ 14/96, iniciouse o processo de regulamentação da lei. Assim, o FUNDEF foi sancionado em 24 de dezembro de 1996, sob a Lei n. ${ }^{\circ}$ 9.424/1996. O FUNDEF foi um fundo de natureza contábil, o que nos é esclarecido pelas palavras de Gemaque (2004, p. 69) "a natureza e a configuração do FUNDEF o caracterizam como um Fundo de gestão, porque sua dinâmica consiste, num primeiro momento, na centralização dos recursos, para depois redistribuílos na proporção do número de matrículas existentes nas respectivas redes de ensino."

No que se refere à questão salarial, a Lei N. ${ }^{\circ}$ 9.424/96, que regulamentou O FUNDEF, consolidou - ou pelo menos se dispôs a tal pretensão - os dispositivos em favor dos professores ao estabelecer, em seu artigo 9..:

Art. 9. Os Estados, o Distrito Federal e os Municípios deverão no prazo de seis meses dispor de novo Plano de Carreira e Remuneração do Magistério, de modo a assegurar:

I - a remuneração condigna dos professores de ensino fundamental público, em efetivo exercício no magistério;

II - o estímulo ao trabalho em sala de aula;

III - a melhoria da qualidade do ensino.

(BRASIL, 1996b).

No artigo apresentado, é claramente expressa a necessidade de elaboração de Planos de Carreira e Remuneração do Magistério Público, de forma a 
assegurar salário condigno², estímulo ao trabalho em sala de aula e melhoria da qualidade de ensino. Além disso, a lei que regulamentou o FUNDEF também estabeleceu que a subvinculação de 60\% dos recursos desse Fundo deveriam ser destinados ao pagamento dos salários dos professores. Como avaliou Melchior (1997)

0 Fundo de Desenvolvimento do Ensino Fundamental e de Valorização do Magistério (FUNDEF) foi criado com a pretensão de garantir recursos mínimos para os alunos do Ensino Fundamental das redes estaduais e municipais, assim como garantir salários mais elevados e valorizar o magistério (MELCHIOR, 1997, p. 10).

Como podemos ver, esse Fundo foi criado tendo como um de seus principais destaques a valorização dos professores. Contudo, mais uma vez, é pertinente destacar que a lei não mostra parâmetros sobre as condições de trabalho e de salário condigno nem deixa claro esse conceito. Nos estudos sobre a efetivação do FUNDEF, a exemplo de Castro (2008), MEC (2007), Gemaque (2008), Arelaro (2007), entre outros, é possível perceber nas análises os seus aspectos positivos e negativos, e que merecem ser abordados.

$\mathrm{Na}$ avaliação do MEC (2005), O FUNDEF representou uma autêntica revolução no atendimento ao Ensino Fundamental nas redes públicas do país, especialmente pelo seu critério redistributivo de recursos. Para esse Ministério, o modelo tornou possível direcionar os recursos reservados à Educação para onde estavam os alunos. A partir da instituição do Fundo, movimentaram-se recursos dos governos com maior capacidade financeira e/ou com um baixo nível de participação no atendimento escolar para os Municípios em situação inversa.

A avaliação do Ministério ainda enfatizava que a reserva de $60 \%$ dos recursos do Fundo para a remuneração do Magistério representou aumentos significativos nos salários dos professores em efetivo exercício da docência no Ensino Fundamental. Entre dezembro de 1997 e junho de 2000, o aumento médio na remuneração dos professores foi de 29,6\%, com destaque para algumas regiões, como a Nordeste,

2 Vale ressaltar que a lei do FUNDEF traz à tona - "nome", porém não apresenta definição do que representa salário condigno para esses profissionais. onde os docentes desse nível de ensino foram beneficiados com um aumento médio de 59,6\%, aí incluídas as redes municipais e estaduais.

Sobre os aspectos positivos, principalmente no que se refere aos salários dos professores, destacamos ainda o que Castro (1998) salienta que é necessário considerar: o papel equalizador existentenestapolítica, quandoressaltaavalorização dos profissionais da educação mediante a melhoria salarial decorrente da subvinculação de parte dos recursos (60\%) à remuneração. Entretanto, a maior parte dos posicionamentos encontrados avalia essa circunstância como frágil.

Essa fragilidade é mostrada nos estudos de Gemaque (2004), Monlevade (2000), Davies (2001) e Arelaro (2007), entre outros autores da área do financiamento da educação, permitindo inferir que os objetivos propostos no FUNDEF, no que diz respeito à valorização dos profissionais da educação, não foram alcançados com êxito; e o primeiro aspecto a ser destacado a esse respeito se relaciona à necessidade de os Estados, o Distrito Federal e os municípios elaborarem seus Planos de Carreira e Remuneração, já que, até os dias atuais, muitos ainda não os possuem.

Outra questão a ser abordada é que, com o FUNDEF, não ocorreu injeção de recursos financeiros novos na educação. Portanto, os 60\% dos recursos do Fundo destinados à valorização do magistério ficaram "[...] longe de possibilitar a sua real valorização, uma vez que esse percentual representou apenas 1/3 dos gastos contábeis em educação" (DAVIES, 2008, p. 53).

Além disso, esses estudos também apontam que os ganhos nos salários dos professores só aconteceram nos estados e municípios em que isso já ocorria e, ainda assim, foram poucos os ganhos salariais, uma vez que se constatou que, mesmo nos municípios pobres, já se gastavam $60 \%$ em pagamento de pessoal. O que se obteve, de maneira geral, foi o estabelecimento de gratificações anuais para o magistério.

Arelaro (2007) afirma que, na avaliação da implantação doFUNDEF realizada em doze Estados, constatou-se que os municípios cujos quais os prefeitos não pagavam sequer o salário mínimo aos professores tiveram efetivamente a correção dessa injustiça. Os prefeitos passaram, a partir de 1999, 
a pagar pelo menos o salário mínimo. Porém, diz a referida autora, para isso não era necessário o FUNDEF. Bastava o cumprimento dos dispositivos da Constituição Federal (CF), de 1988, que proíbe que qualquer trabalhador ganhe menos de um salário mínimo por jornada de trabalho.

Portanto, podemos afirmar que embora a Lei N. ${ }^{\circ}$ 9.424/1996, ao regulamentar o FUNDEF, se referisse a salário condigno para os profissionais da educação, na prática, não foi efetivada nenhuma política salarial específica para esses profissionais de forma que se configurasse de fato em valorização. A esse respeito, concordamos com Davies (2008) e enfatizamos que, exceto a avaliação do MEC, nenhum outro estudo demonstrou que o percentual de $60 \%$ destinado à valorização resultou, necessariamente, em melhoria salarial.

Nas palavras de Pinto (2006):

A Lei N. ${ }^{0}$ 9.424/96 que regulamentou o Fundef, fundo este que tem em seu nome o compromisso com a valorização do magistério, pouco avançou também na definição dos parâmetros que definiriam uma atuação mais adequada por parte dos profissionais e garantiriam, assim, a melhoria da qualidade de ensino (PINTO, 2006, p. 76)

Desta forma, compreendemos que a melhoria das condições de trabalho dos profissionais da educação, por meio de sua valorização salarial, ocorreu somente em algumas regiões do país, principalmente nas redes municipais que apresentavam remuneração inferior ao salário mínimo nacional, pois, como afirma Arelaro (2007), "em outras situações, a melhoria ocorreu por meio de abonos, bonificações, prêmios, entre outras modalidades de complementações salariais não incorporadas ao vencimento", constituindo-se, portanto, em abono transitório. Abonos transitórios não significa melhoria, uma vez que eles podem ser extintos, a depender dos governantes. Contudo, embora o FUNDEF tenha encerrado seu prazo de vigência em 2006, a política de Fundos para financiar a educação continuou.

Em 20 de dezembro de 2006, foi aprovada a EC N. ${ }^{\circ}$ 53, que criou o Fundo de Manutenção e Desenvolvimento da Educação Básica e Valorização dos Profissionais da Educação (FUNDEB), regulamentado em 28 de dezembro de 2006, pela Medida Provisória n. ${ }^{\circ}$ 339, convertida na Lei N. ${ }^{\circ}$. 11.494/2007.

\section{O FUNDEB: origens, concepções e a política salarial para os professores.}

Segundo Callegari (2004), desde 1995 tramitavam no Congresso Nacional inúmeras propostas de Emenda à Constituição, propondo alterações nas disposições sobre o financiamento do ensino público, dentre as quais ele destaca a PEC N. ${ }^{\circ}$ 78, de 25 de abril de 1995; a PEC N. ${ }^{\circ} 112$, de 2 de setembro de 1999; a PEC N. ${ }^{\circ} 82$, de outubro de 1999; PEC N. ${ }^{\circ}$ 2, de fevereiro de 2002; PEC N. ${ }^{\circ}$ 29, de junho de 2002; PEC N. ${ }^{\circ} 34$, de dezembro de 2002; PEC N. ${ }^{\circ}$ 190, de novembro de 2003; PEC N. ${ }^{\circ}$ 45, de dezembro de 2003. Contudo, é importante ressaltar que, das Propostas de Emenda à Constituição apresentadas acima, apenas a PEC N. ${ }^{\circ}$ 112, de 1999, e a PEC N. ${ }^{\circ}$ 34, de 2002, tratam da substituição do FUNDEF pelo FUNDEB.

A proposta de Emenda à Constituição (PEC) n. ${ }^{\circ}$ 112 foi apresentada à Câmara dos Deputados, em setembro de 1999, pelo Deputado Fernando Roque, do Partido dos Trabalhadores (PT), do Paraná. O referido deputado fazia parte do núcleo de Educação do partido, expressando, portanto, uma posição favorável deste último à criação de um Fundo que contemplasse toda a Educação Básica.

Na referida PEC, é dada uma nova redação ao inciso IV, dos artigos 208 e 211, da CF de 1988, em que se percebe a preocupação com a Educação Infantil e a inclusão do Ensino Médio e da Educação de Jovens e Adultos na política de financiamento ali proposta. O $\$ 9 .^{\circ}$, da citada PEC, prevê "a constituição de Fundos Estaduais de Manutenção e Desenvolvimento da Educação Básica Pública e de Valorização dos Profissionais de Educação." (Cf. CALLEGARI, 2004). Visava ainda à disponibilização crescente de recursos da União, do Distrito Federal, dos Estados e Municípios para a Educação Básica. No que se refere à valorização dos profissionais da Educação, a citada PEC anunciava a criação de um Piso Salarial Nacional e previa a destinação de $80 \%$ dos recursos do Fundo para pagamento de professores e funcionários da Educação

Com base em Callegari (2004), destacamos que na Comissão de Constituição e Justiça, da Câmara dos Deputados, em 13 de setembro de 2000, foi apresentada uma Emenda à PEC N. ${ }^{\circ} 112$, na forma de proposta substitutiva. Nesta última, manteve-se 
a lógica de constituição de um fundo para toda a Educação Básica e o valor de oitenta por cento (80\%) dos recursos do fundo a ser aplicados na valorização dos profissionais da educação.

Com base na PEC N. 112/99, só em 2002, foi apresentada pelo Senador Ricardo Santos (do PSDB), a PEC N. ${ }^{\circ} 34 / 02$, na qual se mantinha a constituição de um fundo para toda a Educação Básica; contudo, no $\S 5^{\circ}$, previa-se a destinação não mais de 80 , mas de $60 \%$ dos recursos para o pagamento de professores. Assim ficou a redação: "proporção não inferior a sessenta por cento dos recursos de cada fundo [...] será destinado exclusivamente ao pagamento dos professores da educação básica pública em efetivo exercício no magistério" (CALLEGARI, 2004).

Assim, após apresentadas as diretrizes básicas para constituição do novo Fundo, em 12 de maio de 2005, foi apresentada à Câmara Federal a PEC N. ${ }^{\circ}$ 415/05, de autoria do Executivo Federal, propondo a criação doFundo de Manutençãoe Desenvolvimento da Educação Básica e de Valorização dos Profissionais da Educação - FUNDEB, partindo do princípio de que esse Fundo promoveria um novo realinhamento nas finanças públicas dos Estados, Distrito Federal e Municípios: a partir de uma ampla redistribuição dos recursos vinculados à Educação, permitiria a esses entes federados condições de assegurar universalização do atendimento em todas as etapas, níveis e modalidades de ensino da Educação Básica, mediante garantia de um investimento mínimo por aluno, por nível de ensino, possibilitando a necessária elevação da qualidade social da Educação.

A partir daí, a discussão prossegue no Senado e em 04/07/2006 foi aprovada, em segundo turno, a proposta de Emenda à Constituição N. ${ }^{\circ}$, de 2006 (n. 536/1997, na Câmara dos Deputados) que dispõe sobre o FUNDEB.

A PEC N. ${ }^{\circ} 415 / 2005$ deu origem à Emenda Constitucional N. ${ }^{\circ}$ 53, de dezembro de 2006, promulgada pelo Presidente da República, dando nova redação aos artigos 7, 223, 30, 206, 208, 211 e 212, da Constituição Federal, e ao artigo 60, do $A D C$, e dispondo sobre o FUNDEB. Em dezembro do mesmo ano foi este regulamentado pela Medida Provisória N. ${ }^{\circ}$ 339/2006 e, posteriormente, em lei, em julho de 2007, sob o número 11.494/2007.
Assim, o Fundo de Manutenção e Desenvolvimento da Educação Básica e de Valorização dos Profissionais da Educação (FUNDEB), regulamentado pela Lei $\mathrm{N} .{ }^{\circ}$ 11.494/2007, tem entre seus principais objetivos: promover a equalização, pela distribuição de recursos da Educação entre os Estados e seus municípios; universalizar o atendimento na Educação Básica; reduzir desigualdades, com garantia de investimento mínimo que assegure qualidade do ensino; valorizar os profissionais da educação; e assegurar as condições de garantia de piso salarial nacional para o magistério.

Segundo o 'Relatório de Orientações para o FUNDEB', elaborado pelo MEC (BRASIL, 2008a), trata-se de um Fundo especial, de natureza contábil e de âmbito estadual, ou seja, um Fundo por Estado e Distrito Federal, totalizando 27 Fundos. Esses fundos são formados por parcela de recursos destinados à educação pelas esferas estaduais e municipais e complementados com recursos da esfera federal, quando necessário.

Ao ser adotada a estratégia de definição do valor mínimo por aluno-ano, a partir da "viabilização do possível" por parte da União, o número de Estados e valores recebidos de complementação podem ser observados na Tabela a seguir.

\section{TABELA 1. Número de Estados que recebem complementação da União para o FUNDEB e percentual de participação por Estado (2007-2009) (Em 1000 Reais).}

\begin{tabular}{|c|c|c|c|c|c|c|c|}
\hline \multicolumn{2}{|c|}{ ESTADOS } & $\begin{array}{c}\text { VALOR } \\
2007\end{array}$ & $\%$ & $\begin{array}{c}\text { VALOR } \\
2008\end{array}$ & $\%$ & $\begin{array}{c}\text { VALOR } \\
2009\end{array}$ & $\%$ \\
\hline 01 & Alagoas & 96.335 & 4,8 & 97.272 & 3,1 & 182.283 & 3,6 \\
\hline 02 & Bahia & 391.978 & 19,6 & 774.997 & 24,4 & 1.161 .889 & 22,9 \\
\hline 03 & Ceará & 280.785 & 14,0 & 440.071 & 13,9 & 662.277 & 13,1 \\
\hline 04 & Maranhão & 575.437 & 28,8 & 789.927 & 24,9 & 1.174 .953 & 23,2 \\
\hline 05 & Pará & 471.910 & 24,6 & 801.913 & 25,3 & 1.097 .424 & 21,5 \\
\hline 06 & Paraíba & 26.967 & 1,3 & 3.317 & 0,1 & 126.833 & 2,5 \\
\hline 07 & Pernambuco & 36.640 & 1,8 & 132.974 & 4,2 & 380.436 & 7,5 \\
\hline 08 & Piauí & 99.944 & 5,0 & 133.824 & 4,2 & 247.222 & 4,9 \\
\hline 09 & Amazonas & - & - & - & - & 36.829 & 0,7 \\
\hline Complem. União & 2.000 .000 & 100 & 3.174 .300 & 100 & 5.070 .150 & 100 \\
\hline
\end{tabular}

FONTE: UFPA: GEFIN, 2009 [Relatório parcial do projeto de pesquisa "Acompanhamento e Avaliação do Processo de Implantação do Fundo de Manutenção e Desenvolvimento da Educação Básica e de Valorização dos Profissionais da Educação (FUNDEB) no Estado do Pará]; 
Os dados mostram que, em 2007 e 2008, apenas oito Estados receberam complementação da União, com previsão de inclusão de mais um (Amazonas), em 2009, o que corresponde a apenas 30\% do total de Estados, ou seja, a grande maioria não é contemplada com os recursos da União. Os Estados que receberam os maiores aportes desses recursos foram Maranhão e Pará, que se revezam na posição de menor valor per capita-ano; e os que menos receberam recursos foram Paraíba e Alagoas.

Outro aspecto importante a destacar sobre o FUNDEB se refere aos profissionais da Educação. O artigo 22, inciso II, da Lei N. ${ }^{\circ}$ 11.494/2007 faz esse esclarecimento, quando diz que são considerados profissionais da educação: docentes; profissionais que oferecem suporte pedagógico direto ao exercício da docência (direção ou administração escolar, planejamento, inspeção, supervisão, orientação educacional e coordenação pedagógica). Portanto, todos esses profissionais que estiverem ativos na função podem ser remunerados com os $60 \%$ dos recursos destinados a esse fim. Além disso, entendemos que os pedagogos atuantes em direção, supervisão e orientação escolar que antes eram considerados técnicos, a partir da implementação da lei fazem parte da carreira de magistério. Importa frisar que esses $60 \%$ não podem ser usados para pagamento de funcionários inativos.

Nessa Lei, mais uma vez a valorização dos profissionais da educação é apontada como o aspecto fulcral para a qualidade da Educação, o que fica claro em seu art. 40.

Art. 40. Os Estados, o Distrito Federal e os Municípios deverão implantar Planos de Carreira e remuneração dos profissionais da educação básica, de modo a assegurar:

I- a remuneração condigna dos profissionais na educação básica da rede pública;

II - integração entre 0 trabalho individual e a proposta pedagógica da escola;

III - a melhoria da qualidade do ensino e da aprendizagem.

(BRASIL, 2007).

A referida lei chama atenção para a necessidade de os Estados, Distrito Federal e municípios implantarem seus Planos de Carreira e Remuneração. O salário condigno dos profissionais é um dos aspectos centrais que compõem tal valorização e deverá estar devidamente assegurado nesses Planos.

Além disso, a lei que regulamenta o FUNDEB retoma um aspecto importante para a política salarial dos profissionais da Educação: o estabelecimento de um Piso Salarial Nacional. Essa Lei estabelece, em seu artigo 41, que o Poder Público deveria, até o dia 31 de agosto de 2007, definir o Piso Salarial Profissional Nacional para os profissionais do magistério público da Educação Básica.

\section{Piso Salarial Nacional para os professores: situando o debate.}

A constituição de um Piso Salarial Nacional para os professores é uma luta histórica da categoria, este volta a ser destaque a partir da promulgação da Lei N. ${ }^{\circ} 11.494 / 2007$ que regulamentou o FUNDEB. Desta feita, em agosto de 2007, foi votado na Comissão de Educação e Cultura da Câmara dos Deputados o Projeto de Lei N. ${ }^{\circ}$ 619/2007, apresentado em abril de 2007 pelo Poder Executivo, que estabelecia o valor do PSPN em $R \$ 850,00$, para uma carga horária de 40 horas semanais, o que pode ser considerado o início de um avanço na luta da categoria docente.

SobreessePL, aCNTEsemanifestoueapresentou sua proposta, por meio de um substitutivo, no qual o valor do piso seria de $\mathrm{R} \$ 1.050,00$ (um mil e cinquenta reais), para os professores habilitados em nível médio e de $R \$ 1.575,00$ (um mil quinhentos e setenta e cinco reais), para os habilitados em nível superior - excluídas vantagens e/ou gratificações de qualquer ordem ou natureza, para uma carga horária de 30 horas semanais. Além disso, o substitutivo previa que nenhum gestor fizesse rebaixamento de salário, caso pagasse o valor a mais do que o estipulado no piso.

Contudo, as discussões que antecederam tanto a regulamentação da Lei N. ${ }^{\circ} 11.738 / 2008$ quanto a do substitutivo proposto pela CNTE serviram de base apenas para alterar o valor do piso, de $R \$ 850,00$ para $R \$ 950,00$. A esse respeito, Davies, no início de 2008, fazendo uma análise preliminar do FUNDEB, assinalava:

0 piso de $\mathrm{R} \$ 850,00$ é insignificante, porque em 2010, quando estaria em vigor representaria pouco mais ou pouco 
menos do que dois salários mínimos e corresponderia a uma jornada de 40 horas, ou seja, em tese, esse salário deveria ser suficiente para o profissional manter-se e também a sua família, e esse profissional não teria mais tempo para outra atividade remunerada. 0 piso pode ser "generoso" quando se considera a miséria salarial de professores de municípios mais pobres, porém é um retrocesso em muitos Estados e municípios onde a remuneração hoje supera a fábula de $\mathrm{R} \$ 850,00$. Em outras palavras o piso é nivelado por baixo, sendo contraditório com a intenção declarada de valorização (DAVIES, 2008, p.55).

Quando o Projeto de Lei N. ${ }^{\circ}$ 619/2007 foi apresentado, o discurso era de que $\mathrm{R} \$ 850,00$ era a média salarial dos professores no Brasil, e, nesse sentido, concordamos com Davies (2008) ao dizer que, se fosse para pagar o que já vinha sendo pago aos professores, não seria necessária a efetivação de um piso. O piso deveria tomar como referência os salários que deveriam ser pagos e não os que vinham sendo praticados.

O Piso Salarial Profissional, previsto no FUNDEB, foi regulamentado no dia 16 de julho de 2008, por meio da Lei N. ${ }^{\circ} 11.738 / 2008$.

No que se refere ao valor do piso, é estabelecido que:

Art. 2. 0 piso salarial profissional nacional para os profissionais do magistério público da educação básica será de $R \$ 950,00$ (novecentos e cinquenta reais) mensais, para a formação em nível médio, na modalidade Normal, prevista no art. 62 da Lei n. ${ }^{0} 9.394 / 96$, de 20 de dezembro de 1996, que estabelece as diretrizes e bases da educação nacional (BRASIL, 2008).

A lei aprovada não levou em consideração a proposta apresentada pela CNTE, ao fixar o valor de $\mathrm{R} \$ 950,00$ para os profissionais com formação em nível médio. Outra observação importante se refere ao fato de o piso não ser vinculado à formação, uma vez que é estabelecido apenas para os profissionais com habilitação para o magistério, em nível médio, fato este que não estimula esses profissionais a buscarem formação universitária, nem os habilitados em nível superior a procurarem melhorar suas condições de trabalho. Isso fomenta um processo de desestímulo e de desvalorização no que diz respeito à formação continuada.

Diante disso, é importante destacar as polêmicas que vêm acontecendo a respeito do PSPN, em nível nacional.
Os Estados do Mato Grosso do Sul, Paraná, Santa Catarina, Rio Grande do Sul e Ceará entraram com uma Ação Direta de Inconstitucionalidade do piso (ADIN). Esses Estados alegam não ter orçamento suficiente para cumprir a nova legislação e que os reajustes dos novos valores estariam condicionados à existência de prévia dotação orçamentária e de autorização específica, na Lei de Diretrizes Orçamentárias. Representantes desses Estados dizem que isso não foi feito, em 2008.

A atual Secretária de Educação do Rio Grande do Sul, Mariza Abreu, em entrevista a João dos Santos e Silva, assessor de imprensa do CPERS/ Sindicato (2008), revelou que "o que a lei prevê é impagável e resultará em uma falsa sensação de ganho para a categoria, enquanto não forem divulgados oficialmente os repasses do governo, aumentando o investimento em educação, não existem recursos para aplicar essa lei."

A esse respeito, o Ministro da Educação, Fernando Haddad, tem afirmado em seus pronunciamentos que não faltará verba para a implantação do piso, pois a lei determina que a União deverá destinar recursos aos Estados e Municípios que não conseguirem, com os próprios recursos, arcar com o valor do piso:

Art. $4^{\circ}$ A União deverá complementar, na forma e no limite do disposto no inciso VI do caput do art. 60 do Ato das Disposições Constitucionais Transitórias e em regulamento, a integralização de que trata 0 art. $3^{\circ}$ desta Lei, nos casos em que 0 ente federativo, a partir da consideração dos recursos constitucionalmente vinculados à educação, não tenha disponibilidade orçamentária para cumprir o valor fixado.

$\S 1^{\circ} 0$ ente federativo deverá justificar sua necessidade e incapacidade, enviando ao Ministério da Educação solicitação fundamentada, acompanhada de planilha de custos comprovando a necessidade da complementação de que trata 0 caput deste artigo.

§2 A União será responsável por cooperar tecnicamente com 0 ente federativo que não conseguir assegurar o pagamento do piso, de forma a assessorá-lo no planejamento e aperfeiçoamento da aplicação de seus recursos (BRASIL, 2008).

No que tange à carga horária, a lei prevê que esse valor estipulado para o piso seja equivalente a uma carga horária de 40 horas semanais, ficando assim estruturado: 
Art. $2^{0}[\ldots]$

$\S 1^{\circ} 0$ piso salarial profissional nacional é 0 valor abaixo do qual a União, os Estados, o Distrito Federal e os Municípios não poderão fixar o vencimento inicial das Carreiras do magistério público da educação básica, para a jornada de, no máximo, 40 (quarenta) horas semanais. [...]

$\S 4^{0} \mathrm{Na}$ composição da jornada de trabalho, observar-se-á 0 limite máximo de 2/3 (dois terços) da carga horária para 0 desempenho das atividades de interação com os educando (BRASIL, 2008).

Os governadores dos Estados supracitados também questionam e são contrários à composição da carga horária, quando se estabelece $1 / 3$ desta para planejamento. A esse respeito, o presidente da Confederação Nacional dos Municípios, Paulo Ziulkoski, registra criticamente que a lei aumenta de $25 \%$ para $33 \%$ o tempo de jornada de trabalho que o professor deverá dedicar à atividade extracurricular. Em suas palavras: "a lei cria um buraco e as prefeituras terão de contratar professores, alguém fez esse cálculo?" - indaga o presidente. Além disso, o que os Estados e Municípios questionam a esse respeito é que a lei fere o pacto federativo que dá autonomia para estes entes federados preverem essas situações, nos Planos de Cargos e Carreiras.

A reivindicação dos Estados sobre a inconstitucionalidade da Lei N. ${ }^{\circ}$ 11.738/2008 está sendo acompanhada pela Campanha Nacional pelo Direito à Educação ${ }^{3}$, que assim se pronunciou:

Um novo princípio foi reconhecido no ordenamento jurídico brasileiro a partir da Emenda Constitucional N. ${ }^{0}$ 53/2006: 0 piso salarial profissional nacional para os profissionais da educação escolar pública (art. 206, VIII CF). Para ser efetivado, no entanto, esse princípio precisaria ser regulamentado por uma lei federal, conforme manda a própria Constituição, o que se realizou com a Lei N. ${ }^{0} 11.738$, de 16 de julho de 2008.

Após ser sancionada, porém, a referida Lei teve sua constitucionalidade questionada junto ao Supremo Tribunal Federal (STF), por meio da Ação Direta de Inconstitucionalidade N. ${ }^{\circ} 4167$ (ADIN 4167), promovida

\footnotetext{
3 A Campanha Nacional pelo Direto à Educação é uma articulação de mais de $\mathbf{2 0 0}$ movimentos e organizações da sociedade civil que atuam para que todo cidadão tenha garantido o seu direito a uma educação pública de qualidade. Esta campanha faz parte de mobilizações mundiais, como a Campanha Latino-americana e a Campanha Global de Educação. Disponível em: www. campanhaeducacao.org.br. Acesso em: dez. 2009.
}

por governadores de cinco Estados - Ceará, Mato Grosso do Sul, Paraná, Rio Grande do Sul e Santa Catarina. Os governadores questionaram na ADIN alguns aspectos que delimitam a forma de implementação do piso: (i) a menção à jornada de 40 (quarenta) horas semanais; (ii) a forma de composição da jornada de trabalho, garantindo-se no mínimo 1/3 (um terço) da carga horária para a realização de atividades de planejamento e preparação pedagógica; (iii) a vinculação do piso salarial ao vencimento inicial das carreiras dos profissionais do magistério da educação básica pública; (iv) os prazos de implementação da lei; e (v) a própria vigência da Lei.

Como mencionamos no boletim anterior, alguns desses pontos são muito importantes para que se alcance a efetiva valorização dos trabalhadores (AÇÃO EDUCATIVA, 2009, [online]).

Concordamos com os membros da Campanha no sentido de que a Lei N. ${ }^{0} 11.494 / 2007$, que traz à tona regulamentação do PSPN paraos professores, é o reconhecimento de uma luta histórica destes últimos. No entanto, os efeitos dessa lei podem ser nulos se esta realmente não apresentar critérios claros e bem definidos sobre remuneração docente e, principalmente, clareza sobre vencimento básico e remuneração na carreira magisterial.

Segundo o Dicionário de Economia (2008), o salário é geralmente o principal rendimento auferido pelas famílias. É o salário que determina o consumo dessas mesmas famílias. Por este motivo, o salário é analisado não apenas em termos monetários (o chamado salário nominal), mas também em termos da quantidade de bens que com ele se consegue adquirir (o salário real). Desta forma, a questão das variações salariais está intimamente ligada às variações dos preços. Se, por exemplo, os salários aumentarem menos do que o nível geral de preços (ou seja, do que a inflação), a quantidade de bens que os trabalhadores conseguem adquirir reduz-se; isto é, apesar de o salário nominal ter aumentado, o salário real reduziu-se. Diz-se que os trabalhadores sofreram uma quebra no poder de compra.

Para o DIEESE (2008), existe uma confusão conceitual entre salário e remuneração. Nesse estudo, com base no próprio DIEESE, partimos do pressuposto de que há uma distinção entre esses conceitos e concebemos o salário como uma parcela da remuneração total do trabalhador. O salário seria, portanto, o básico, e a remuneração é o salário básico somado a demais gratificações e abonos. 
Para tanto, é necessário termos esclarecimento do que é vencimento base e o que é remuneração para o funcionalismo público.

A lei N. ${ }^{\circ} 8.112$, de 11 de dezembro de 1990 que Dispõe sobre o Regime Jurídico dos Servidores Públicos Civis da União, das Autarquias e das Fundações Públicas Federais estabelece, no art. 40, que "Vencimento é a retribuição pecuniária pelo exercício de cargo público, com valor fixado em lei."; e o art. 41 que "Remuneração é o vencimento do cargo efetivo, acrescido das vantagens pecuniárias permanentes estabelecidas em lei."

Além disso, destacamos ainda que para o professor Claudio José Silva, autor do artigo Sistema Remuneratório dos Servidores, a Lei n. ${ }^{\circ}$ 8.852 de 4 de fevereiro de 1994, veio consagrar no ordenamento jurídico a distinção acima citada, preceituando em seu artigo $1 .{ }^{\circ}$

Art. $1^{0}$ - Para os efeitos desta Lei, a retribuição pecuniária devida na Administração pública direta, indireta e fundacional de qualquer dos Poderes da União compreende:

I - Como vencimento básico:

a) A retribuição a que se refere 0 artigo 40 da Lei n. ${ }^{0} 8.112$, de 11 de dezembro de 1990, devida pelo efetivo exercício do cargo, para o servidores civis por ela regidos. [...]

b) Como vencimentos, a soma do vencimento básico com as vantagens permanentes relativas ao cargo, emprego, posto ou graduação.

c) Como remuneração, a soma dos vencimentos com adicionais de caráter individual e demais vantagens, nestas compreendidas as relativas à natureza ou ao local de trabalho e a prevista no art. 62 da Lei n. ${ }^{0} 8.112 / 90$, ou outra paga sob o mesmo fundamento [...] (BRASIL, 1994).

No que se refere aos $R \$ 950,00$, como piso, a decisão temporária do Supremo Tribunal Federal é de que esse valor deve ser considerado como remuneração, e não como vencimento básico, o que torna ainda pior a política salarial para os profissionais do magistério da Educação Básica, pois

Com a decisão do tribunal, o piso salarial passa a corresponder à remuneração mínima a ser paga aos profissionais do magistério, e não ao vencimento inicial mínimo, como estabelece o parágrafo $1 .{ }^{\circ}$, do art. $2 .{ }^{\circ}$ da Lei n. ${ }^{0} 11.738 / 2008$. A consequência prática dessa interpretação é a possibilidade de serem consideradas na composição do valor do piso (de $\mathrm{R} \$ 950,00$ segundo
0 caput do art. $2^{\circ}$ da Lei) todas as complementações salariais que não compõem o vencimento-base da carreira docente. 0 que não pode ser inferior ao piso assegurado não é mais, como determina a Lei, o vencimento-base inicial da carreira, mas o que efetivamente se recebe 0 total da remuneração do profissional, somando-se para isso vencimento-base, gratificações e vantagens (AÇÃO EDUCATIVA, 2009 [online]).

Para melhor reflexão sobre o salário proposto aos professores com o PSPN e que está sendo motivo de inúmeras discussões, dúvidas, angústias por parte dos professores, apresentamos, no Quadro 7, as informações do Departamento Intersindical de Estatísticas e Estudos Socioeconômico (DIEESE, 2008) sobre os valores dos salários necessários para uma família viver relativamente bem, usufruindo do mínimo necessário para uma vida saudável.

\begin{tabular}{|c|c|c|}
\hline PERÍ0D0 & $\begin{array}{c}\text { SALÁRI0 MÍNIM0 } \\
\text { NOMINAL }\end{array}$ & $\begin{array}{c}\text { SALÁRI0 MÍNIM0 } \\
\text { NECESSÁRI0 }\end{array}$ \\
\hline JAN/2008 & $\mathrm{R} \$ 380,00$ & $\mathrm{R} \$ 1.924,59$ \\
\hline $\mathrm{FEV} / 2008$ & $\mathrm{R} \$ 380,00$ & $\mathrm{R} \$ 1.900,32$ \\
\hline $\mathrm{MAR} / 2008$ & $\mathrm{R} \$ 415,00$ & $\mathrm{R} \$ 1.882,32$ \\
\hline $\mathrm{ABRIL} / 2008$ & $\mathrm{R} \$ 415,00$ & $\mathrm{R} \$ 1.918,12$ \\
\hline $\mathrm{MAIO} / 2008$ & $\mathrm{R} \$ 415,00$ & $\mathrm{R} \$ 1.987,51$ \\
\hline $\mathrm{JUN} / 2008$ & $\mathrm{R} \$ 415,00$ & $\mathrm{R} \$ 2.072,70$ \\
\hline $\mathrm{JUL} / 2008$ & $\mathrm{R} \$ 415,00$ & $\mathrm{R} \$ 2.178,30$ \\
\hline $\mathrm{AGO} / 2008$ & $\mathrm{R} \$ 415,00$ & $\mathrm{R} \$ 2.025,99$ \\
\hline $\mathrm{SET} / 2008$ & $\mathrm{R} \$ 415,00$ & $\mathrm{R} \$ 1.971,55$ \\
\hline OUT/2008 & $\mathrm{R} \$ 415,00$ & $\mathrm{R} \$ 2.014,73$ \\
\hline $\mathrm{NOV} / 2008$ & $\mathrm{R} \$ 415,00$ & $\mathrm{R} \$ 2.007,84$ \\
\hline $\mathrm{DEZ} / 2008$ & $\mathrm{R} \$ 415,00$ & $\mathrm{R} \$ 2.141,08$ \\
\hline $\mathrm{JAN} / 2009$ & $\mathrm{R} \$ 415,00$ & $\mathrm{R} \$ 2.077,15$ \\
\hline
\end{tabular}

\section{QUADRO 7. Salário mínimo nominal e necessário (jan/2008 - jan/2009)}

FONTE: DIEESE, 2008.

Ao comparar esses valores com o valor do PSPN, percebemos que este, da forma como está estabelecido, é consideravelmente inferior ao salário necessário para se ter o mínimo necessário para uma vida saudável, e o salário deveria ser para o professor, assim como para as demais categorias de trabalhadores, um direito social constitucional do cidadão, como expressa o art. $7 .^{\circ}$, inciso IV, da CF/1988:

Art. $7^{\circ}$ São direitos dos trabalhadores urbanos e rurais, além de outros que visem à melhoria da sua condiçã̃o social:

[...]

IV - salário mínimo, fixado em lei, nacionalmente unificado, capaz de atender às suas necessidades vitais 
básicas e a de sua família com moradia, alimentação, educação, saúde lazer, vestuário, higiene, transporte e previdência social, com reajustes periódicos que Ihe preservem o poder aquisitivo, sendo vedada sua vinculação para qualquer fim (BRASIL, 1988).

Vemos que, constitucionalmente, é garantido aos trabalhadores um salário suficiente para atender as suas necessidades vitais básicas; porém, os salários que vêm sendo estabelecidos, como mostra o DIEESE, não oferecem condições de atender a essas necessidades dos trabalhadores, e o valor do PSPN, por ora, está distante de atender às necessidades vitais básicas do professorado.

No Estado do Pará, segundo informações do SINTEPP, ainda não houve discussões específicas para se tratar sobre o piso; o que por hora está acontecendo são as discussões sobre o Plano de Cargos, Carreira e Remuneração (PCCR) unificado dos professores desse Estadoe, nessas discussões, o PSPN é um dos destaques. Para fins de situar os debates que estão acontecendo, apresentamos as principais linhas das pautas negociadas pelo Sindicato dos Professores do Estado do Pará com o governo sobre a valorização docente, a destacar: Piso salarial estadual;

Jornada de 20 horas com um salário mínimo do DIEESE; Aprovação imediata do PCCR unificado; Incorporação dos abonos e gratificações;

Pagamento das perdas históricas, corrigidas até a database da categoria;

Revisão dos vencimentos-base dos técnicos/pedagogos com pagamento imediato e equiparação com os profissionais do magistério;

Gratificação de nível superior para o professor ad1 que possua graduação;

Pagamento de abonos para todos os trabalhadores em educação pagamento insalubridade para serventes $\mathrm{e}$ merendeiras;

Pagamento da progressão horizontal;

Pagamento da gratificação de função para secretários e diretores;

Pagamento de recesso a todos os trabalhadores em educação;

Fim do desconto previdenciário sobre $013^{\circ}$ salário; garantir a licença prêmio para os trabalhadores em educação como determina o RJU;

Melhoria das condições de trabalho; implementação do programa de saúde do trabalhador, para atender as necessidades da categoria;

Extensão do vale-transporte para todos os municípios, onde exista transporte urbano / cartão de vale-transporte para a região metropolitana de Belém;

Ticket-alimentação de $\mathrm{R} \$ 300,00$; pecúlio - pagamento em forma de indenização; realizar auditoria nos recursos destinados ao FUNDEF, repassados pelo governo federal, a título de compensação da lei Kandir;

Redefinição do calendário escolar sem sábados letivos;

Desmunicipalização do ensino; gestão democrática com o fortalecimento dos conselhos escolares, fortalecimento das organizações estudantis e eleição direta para diretor em todas as escolas e URES do estado;

Extinção dos pólos; suspensão imediata dos descontos no contracheque e instalação de auditória; fim da ouvidoria (SINTEP, 2009).

Como podemos ver, na pauta das discussões e reivindicações sobre valorização docente, no Estado do Pará, em negociação entre governo e sindicato, além de inúmeros outros fatores que caracterizam essa valorização, a questão do piso salarial está presente; porém, o debate específico sobre o piso ainda não aconteceu de fato.

\section{Finalizando}

Na década de 1990, vimos que no aspecto educacional, a ideia de política de fundos é retomada, e um dos aspectos centrais é a valorização do profissional do magistério por meio de condições de trabalho adequadas, qualificação profissional e salário condigno. No entanto, faltou serem definidos critérios reais do que seria salário condigno para o professor; portanto, também essa valorização se manteve no campo ideológico.

Verificamos ainda outra política de fundo que surgiu na primeira década do século $X X I$, o FUNDEB, e com ela políticas salariais que acenam para uma pretensa valorização de tais profissionais, especificamente para os professores. A demanda que se apresenta é a de verificar como essa política vem impactando o salário desses profissionais e se a mesma comporta a propalada valorização, uma vez que se defende a perspectiva de que uma política salarial digna para os profissionais da educação constitui um dos elementos para a melhoria e qualidade da educação.

Assim, concordamos com o CNTE de que o FUNDEB até pode ter a prerrogativa de aumentar os recursos em todas as etapas e modalidades da educação básica, porém, seus efeitos podem ser 
nulos, caso não seja realmente priorizada a política de valorização dos profissionais da Educação.

No que diz respeito ao PSPN, ainda é cedo para avaliar. Porém, o que as realidades vêm nos mostrando é que há muitas confusões no aspecto salarial dos professores a partir da implementação desta lei. O que está parecendo é que a Lei do piso pode até trazer melhorias para aquelas realidades em que o professor ainda ganha um salário mínimo por 20 horas de trabalho semanal, porém para outras realidades em que os professores recebem mais de quinhentos reais $(R \$ 500,00)$ por 20 horas de trabalho semanais pode significar um retrocesso, visto que o valor de novecentos e cinquenta reais $(R \$ 950,00)$ foi estabelecido para 40 horas de trabalho semanais. Se este valor for concebido como a remuneração total dos professores - o que aliás revela uma falha da própria lei, ao não distinguir vencimento de remuneração - o ideal de valorização por meio de um salário digno ainda não irá acontecer dessa vez.

\section{Referências Bibliográficas}

ARELARO, Lisete Regina Gomes. FUNDEF: uma avaliação preliminar dos dez anos de sua implantação. GT 5 Estado e Política Educacional. s/d.

BRASIL, Constituição (1988). In: PESSOA, Fernanda. Legislação Educacional 3 em 1. São Paulo: RCN Editora. 2005.

BRASIL, lei n. ${ }^{0} 11.738$. Regulamenta a alínea "e" do inciso III do caput do art. 60 do Ato das Disposições Constitucionais Transitórias, para instituir o piso salarial profissional para os profissionais do magistério público da educação básica.

BRASIL, Lei n. 9.394 de 20.12.1996, Estabelece as Diretrizes e bases da educação Nacional. In: PESSOA, Fernanda. Legislação Educacional 3 em 1. São Paulo: RCN Editora. 2005.

BRASIL, Lei ñ. 9.424, de 24 de dezembro de 1996. Dispõe sobre o Fundo de Manutenção e Desenvolvimento do Ensino Fundamental e de Valorização do Magistério (FUNDEF).

DAVIES, Nicholas. O FUNDEF e as verbas da educação. São Paulo: Xamã, 2001

FUNDEB: A redenção da educação básica. Col. Polêmicas do Nosso Tempo. Campinas: Autores Associados, 2008.

GEMAQUE, Rosana Maria Oliveira. Financiamento da Educação, O FUNDEF no Estado do Pará: Feitos e Fetiches. Tese (Doutorado em Educação). Universidade de São Paulo: São Paulo, 2004.

HARVEY, David. Condição Pós-Moderna. São Paulo. Loyola, 2003.

MARE. Cadernos MARE da Reforma do Estado. Brasília, 1997.

MONLEVADE, João A. C. Valorização Salarial dos Professores. 2000. Tese (Doutorado em Educação). Universidade Estadual de Campinas, Campinas, setembro de 2000.

PERONI, Vera. Política Educacional e papel do Estado: no Brasil dos anos de 1990, São Paulo: Xamã, 2003.

PINTO. Marcelino José. O Custo Aluno Qualidade Inicial (CAQI) no contexto do Fundeb e dos limites do pacto federativo. (Palestra proferida para os alunos do Programa de Pós-graduação da UFPA), Belém- Pará, 2008.

RAMOS, Ângela Maria Pinheiro. O Financiamento da Educação Brasileira no contexto das mudanças políticoeconômicas pós-90. Brasília: Plano Editora, 2003.

SILVA, Ilse Gomes. Democracia e Participação na Reforma do Estado. São Paulo: Cortez, 2003

TOMMASI, Lívia de. Financiamentos do Banco Mundial no setor educacional brasileiro: os projetos em fase de implementação. In: HADDAD, Sérgio et all (orgs). 0 Banco Mundial e as Políticas Educacionais.5ª ed. São Paulo:Cortez, 2007.

TORRES, Rosa Maria. Melhorar a qualidade da educação básica? As estratégias do Banco Mundial. In: HADDAD, Sérgio et all (orgs). 0 Banco Mundial e as Políticas Educacionais.5ª ed. São Paulo:Cortez, 2007.

VALLE, BerthadeBorja Reis do. Formulação dos planos de cargos e salários e estatutos do magistério: a nova legislação. In SOUZA, Donaldo Bello de \& FARIA, Lia Ciomar Macedo de (Orgs.). Desafios da Educação Municipal. Rio de Janeiro: DP\&A Editora, 2003. 